\title{
Fast Screening of Solvents for Simultaneous Extraction of Furfural, 5-Hydroxymethylfurfural and Levulinic Acid from Aqueous Solution Using SMD Solvation Free Energies
}

\author{
Ellen V. Dalessandro and Josefredo R. Pliego Jr.* \\ Departamento de Ciências Naturais, Universidade Federal de São João del-Rei, \\ 36301-160 São João del-Rei-MG, Brazil
}

\begin{abstract}
Acid catalyzed decomposition of $\mathrm{C}_{5}$ and $\mathrm{C}_{6}$ sugars has been considered an important source of biomass derived chemicals. An essential step in this process is the extraction of furfural, hydroxymethylfurfural and levulinic acid from aqueous phase. In this work, a computational screening of 178 organic solvents for simultaneous extraction of these chemicals from aqueous phase has been done with the continuum SMD (solvation model based on density) model. Our analysis has taken in account the partition coefficient, water miscibility, boiling point and toxicity of the organic solvents. The present theoretical results indicate that $\mathrm{C}_{6}$ and $\mathrm{C}_{7}$ ketones are the most adequate solvents, and 4-heptanone is predicted to be particularly useful.
\end{abstract}

Keywords: partition coefficient, green chemistry, MIBK, 4-heptanone, tributyl phosphate

\section{Introduction}

Petroleum remains as the main source of feedstock for manufacture of fuels and chemicals. Nevertheless, the increased concern on environmental problems related to carbon dioxide emissions and the petroleum dependence have encouraged the development of biomass based fuels and chemicals. ${ }^{1-5}$ Among the different processes for biomass transformation, acid catalyzed hydrolysis of xylan and glycan components of wood to form $\mathrm{C}_{5}$ and $\mathrm{C}_{6}$ sugars have received attention. ${ }^{6}$ In the catalytic process, xylose and glucose (or fructose) are transformed to furfural, 5-hydroxymethylfurfural (HMF) and levulinic acid via acid-catalyzed dehydration (Scheme 1).

In the acid medium used for generation of the products, more degradation can take place, leading to formic acid.

$$
\mathrm{C}_{5} \text { sugars } \stackrel{\mathrm{H}^{+}}{\Delta} \underset{\text { furfural }}{\longrightarrow} \stackrel{\mathrm{H}}{\stackrel{\mathrm{H}^{+}}{\longrightarrow}} \underset{\text { formic acid }}{\mathrm{O}}
$$<smiles>CC(=O)CCC(=O)O</smiles>

5-hydroxymethylfurfural<smiles>O=CC(O)C(=O)Cl</smiles>

Scheme 1. Formation of furfural, HMF and levulinic acid from acid catalyzed dehydration of $\mathrm{C}_{5}$ and $\mathrm{C}_{6}$ sugars.

\footnotetext{
*e-mail: pliego@ufsj.edu.br
} 
Current processes for recovering of furfural makes use of steam. However, the yield is limited and recently the use of solvent extraction has been advocated as more effective process. ${ }^{6,7}$ In the same way, extraction of HMF during the reaction is desirable because it avoids degradation of this compound. ${ }^{5}$ An efficient extraction requires an adequate solvent, which should have low miscibility with water and lead to a high partition coefficient for each compound. Recent experimental studies have investigated different solvents for extraction ${ }^{7-10}$ and some authors have suggested that 2-butanol and 2-butanone are effective for HMF, while methyl isobutyl ketone (MIBK) is effective for both HMF and furfural compounds. ${ }^{5,6,9}$ Other possibility for identifying efficient solvents for extraction is via computational methods. Thus, Sandler and co-workers ${ }^{11}$ have used the COSMO-SAC method to investigate the ability of several linear and branched alcohols to extract HMF from aqueous solution and have found that the method produces reasonable partition coefficients. Following this work, Blumenthal et al. ${ }^{12}$ have reported a very extensive screening of solvents for extraction of HMF using the COSMO-RS method and they have suggested 110 potential solvents superior to that in use.

A theoretical approach which allows fast screening of solvents for extraction is the SMD (solvation model based on density). ${ }^{13}$ In special, the SMD method is an implicit solvation model with parameters for 179 solvents, including water. Recent tests with the model for solvation in methanol, acetonitrile and dimethyl sulfoxide (DMSO) solvents have indicated a reasonable performance, although higher deviations was observed for DMSO. ${ }^{14}$ The method was also tested for liquid-liquid equilibria using a regular solution-like model and has worked very well. ${ }^{15}$ Marenich et al. ${ }^{16}$ have also tested the model for the SAMPL1 solvation challenge in aqueous solution and the method had a performance as well as explicit solvent approach. ${ }^{16,17}$ Thus, with an adequate automation for generating the input and reading of the output, it is possible to calculate the solvation free energy of any solute into all these 179 solvents very efficiently. Based on these considerations, the aim of this work is to identify the best potential solvents for simultaneous extraction of furfural, hydroxymethylfurfural and levulinic acid from aqueous solution using the SMD model.

\section{Methodology}

Geometries of furfural, HMF and levulinic acid were obtained by quantum chemistry calculations at X3LYP/6-31(+)G(d) level of theory. ${ }^{18}$ The X3LYP functional is similar to the popular B3LYP one. However, it is slightly more accurate. Considering the same computational cost of both functionals, we have decided to use the X3LYP method. Following geometry optimizations, it was done single point energy calculations with the SMD method $^{13}$ using the X3LYP/6-31(+)G(d) electronic density to obtain the solvation free energy of the solutes for each of the 179 solvents. All these calculations were done with the GAMESS program. ${ }^{19,20}$

Because the single point solvation calculations involve a set of very similar inputs and outputs, it was devised a code in the Python programming language to automate this part of the calculations. The created program (called SNAPY) builds the input files, generates the executable and read the solvation free energy values for the chosen structure in 179 solvents available in the SMD model in GAMESS. The SNAPY reduces the time of building the inputs and taking the data from outputs to a small fraction of the time spent doing the same thing manually.

The values of the solvation free energy for each solute in aqueous $\left(\Delta \mathrm{G}_{\text {solv }}^{\mathrm{w}}\right)$ and organic $\left(\Delta \mathrm{G}_{\text {solv }}^{\text {org }}\right)$ solvents are related to the partition coefficient $\left(\mathrm{K}_{\mathrm{c}}\right)$ by equations 1 and 2 :

$\mathrm{K}_{\mathrm{c}}=\frac{[\text { solute }]_{\text {org }}}{[\text { solute }]_{\mathrm{w}}}=\mathrm{e}^{-\Delta \Delta \mathrm{G}_{\text {solv }} / \mathrm{RT}}$

$\Delta \Delta \mathrm{G}_{\mathrm{solv}}=\Delta \mathrm{G}_{\mathrm{solv}}^{\mathrm{org}}-\Delta \mathrm{G}_{\mathrm{solv}}^{\mathrm{w}}$

Equation 2 defines the free energy of transfer of the solute from water to organic solvent. The calculated values correspond to infinity dilution solutions and more negative value is related to better extraction.

In the search of data from literature, many reported values of partition coefficients are in mass fraction $\left(\mathrm{K}_{\mathrm{w}}\right)$ or molar fraction $\left(\mathrm{K}_{\mathrm{x}}\right)$. Thus, we have done the conversion considering the infinity dilution case by the relations:

$$
\begin{aligned}
& K_{c}=K_{w} \frac{\rho_{\text {org }}}{\rho_{w}} \\
& K_{c}=K_{x} \frac{\rho_{\text {org }} M_{w}}{\rho_{w} M_{o r g}}
\end{aligned}
$$

The $\rho$ corresponds to solvent density and $\mathrm{M}$ the molar mass. Following the determination of $\mathrm{K}_{\mathrm{c}}$ from experimental $\mathrm{K}_{\mathrm{w}}$ and $\mathrm{K}_{\mathrm{x}}$, the free energy of transfer from water to organic solvent is obtained by:

$\Delta \Delta \mathrm{G}_{\mathrm{solv}}(\mathrm{w} \rightarrow$ org $)=-\mathrm{RT} \ln \mathrm{K}_{\mathrm{c}}$

\section{Results and Discussion}

The solvation free energy of the three solutes in the 179 solvents available in the SMD model were calculated 
and are presented in the Tables S1, S2 and S3 in the Supplementary Information. The solvents are ordered, taking as reference the free energy of transfer from water to the organic solvent.

It is worth to do a comparison of the SMD prediction with the available experimental data for furfural and HMF. These data are presented in Figure 1 and Table S4. We can observe that there is a correlation between theoretical and experimental free energy of transfer. However, the error is meaningful, with a mean signed error of $-1.2 \mathrm{kcal} \mathrm{mol}^{-1}$. With the linear fit, the corresponding adjusted $\mathrm{R}^{2}$ (coefficient of determination) is found to be 0.50 . We can notice there is a systematic deviation, with the theoretical values being more negative. This error in the free energy of transfer can be attributed to two sources. First, the error in the SMD solvation free energy. In a recent study, the mean unsigned error was in the range of 0.5 to $1.0 \mathrm{kcal} \mathrm{mol}^{-1}$ for simple organic molecules in the organic solvents methanol, dimethyl sulfoxide and acetonitrile. ${ }^{14}$ In the case of more functionalized molecules, like those studied in this work, the error is probable to be even higher. Second, the use of infinity dilution condition in the SMD calculations. Many organic solvents can have reasonable miscibility with water and the phases are not pure. A model that takes in account this effect would be more reliable.

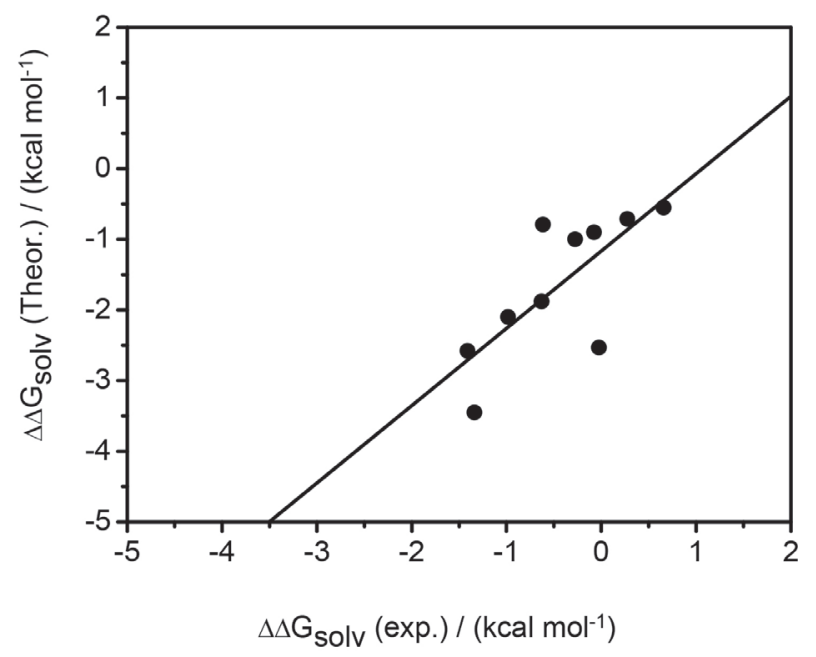

Figure 1. Correlation between theoretical and experimental free energy of transfer from water to organic solvent for furfural and HFM. The added curve is the fitted one and leads to adjusted $\mathrm{R}^{2}=0.50$. Experimental data from references 7-11.

In the selection of solvents for simultaneous extraction of furfural, $\mathrm{HMF}$ and levulinic acid, we have done an analysis to suggest solvents with the highest partition coefficients for all the solutes. In addition, the solvents must have low miscibility with water, boiling point below $162^{\circ} \mathrm{C}$ (furfural boiling point) and, preferentially, low toxicity. Thus, the manual analysis of the results has led us to suggest most adequate solvents. Table 1 presents some solvents that deserves discussion. In general, we have observed that the calculations predict that ketones are superior to ethers, carboxylic esters, pyridines and apolar solvents such as aliphatic hydrocarbons, aromatic hydrocarbons and organic halogens for extraction. The widely used MIBK ketone is predicted to be a good solvent. However, this study suggests that $\mathrm{C}_{7}$ ketones are superior due to similar extraction ability and lower solubility in water. Other ketone, 2-butanone, has been used recently. Despite its good free energy of transfer, it is highly soluble in water and based on our criteria, 2-butanone would not be a good choice.

Table 1. Some solvents for extraction of furfural, HMF and levulinic acid

\begin{tabular}{|c|c|c|c|c|}
\hline \multirow[b]{2}{*}{ Solvent } & \multicolumn{3}{|c|}{ 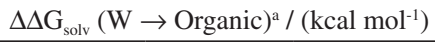 } & \multirow{2}{*}{$\begin{array}{c}\text { Aqueous } \\
\text { solubility / } \\
\left(\mathrm{g} \mathrm{L}^{-1}\right)\end{array}$} \\
\hline & Furfural & HMF & $\begin{array}{l}\text { Levulinic } \\
\text { acid }\end{array}$ & \\
\hline $\begin{array}{l}\text { Tributyl } \\
\text { phosphate }\end{array}$ & -3.47 & -3.21 & -4.29 & 0.4 \\
\hline MIBK & -3.45 & -2.53 & -2.79 & 18 \\
\hline 2-Hexanone & -3.35 & -2.41 & -2.67 & 17 \\
\hline 4-Heptanone & -3.34 & -2.40 & -2.66 & 3.2 \\
\hline 2-Heptanone & -3.24 & -2.27 & -2.54 & 4.3 \\
\hline 2-Pentanone & -3.51 & -2.61 & -2.86 & 55 \\
\hline 2-Butanone & -3.49 & -2.58 & -2.83 & $2.2 \times 10^{2}$ \\
\hline Butyronitrile & -3.39 & -2.31 & -2.38 & 3.8 \\
\hline Benzonitrile & -3.24 & -2.15 & -2.19 & 4.3 \\
\hline Fluorobenzene & -3.37 & -2.10 & -1.95 & 1.6 \\
\hline
\end{tabular}

${ }^{a}$ Free energy of transfer of the solute from water to organic solvent, calculated by the SMD/X3LYP/6-31(+)G(d) method; bexperimental solubility of the organic solvent in water.

Two other solvents have attracted our attention: tributyl phosphate and butyronitrile. In fact, based on the calculated free energy of transfer, tributyl phosphate is a very effective extractor, especially for HMF and levulinic acid. In addition, it has low solubility in water. Nevertheless, this solvent presents very high boiling point, $289^{\circ} \mathrm{C}$. Thus, posterior separation by distillation of the solute would be difficult in the case of HMF and levulinic acid due to high boiling points of these solutes. The other solvent, butyronitrile, is less efficient in the extraction of HMF and levulinic acid than tributyl phosphate. However, it also has low solubility in water (lower than MIBK), and a boiling point of $116^{\circ} \mathrm{C}$, close to MIBK value of $117^{\circ} \mathrm{C}$. Its ability of extraction of furfural and HMF is close to MIBK. A negative point is its toxicity, which could make this solvent less attractive.

Other interesting solvent found was fluorobenzene. Although it is less effective extractor for furfural and HMF 
$-0.4824$<smiles>CCCOc1ccco1</smiles>

Furfural

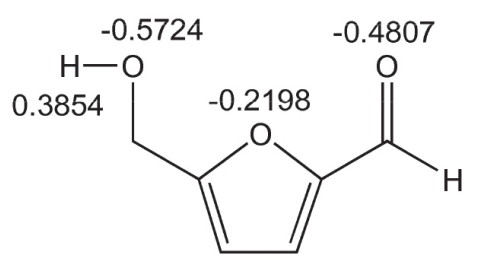

hydroxymethylfurfural

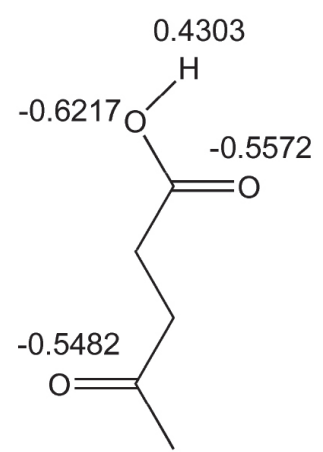

Levulinic acid<smiles>CC(=O)CC(C)C</smiles>

methyl isobutyl ketone

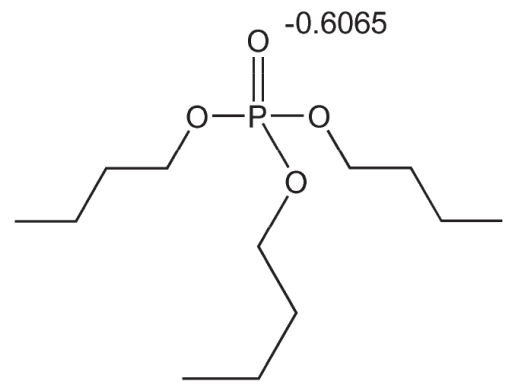

tributyl phosphate

Scheme 2. Selected atomic charges, in units of electron charge, determined by the geodesic method (charges based on the electrostatic potential).

than the ketones, and even less effective for levulinic acid, it has very low solubility in water and a boiling point of only $85{ }^{\circ} \mathrm{C}$.

Aiming to better understand the effectivity of ketones, and the even more effective extraction ability of tributyl phosphate, it was calculated the atomic charges of some atoms of the solutes and of the solvents MIBK and tributyl phosphate. The charges were determined by the geodesic method of Spackman, ${ }^{21}$ based on charges fitted to reproduce the electrostatic potential, and using the X3LYP/TZVPP electronic density (Scheme 2). The values of charges are very negative on the oxygens of the MIBK and the tributyl phosphate, suggesting strong hydrogen bond with the solutes. In special, HMF and levulinic acids have very positive hydrogens, while in furfural the hydrogen of the -CHO group has small charge. The carbon in this group, which has a very positive charge, can be important for interaction with the oxygens of the solvents.

We have also investigated the van der Waals complexes involving HMF with MIBK and tributyl phosphate, which are presented in Figure 2. It is evident the formation of hydrogen bonds. The calculated interaction energies can rationalize the better extraction of HMF with tributyl phosphate than with MIBK. In fact, the hydrogen bond is almost $2 \mathrm{kcal} \mathrm{mol}^{-1}$ more negative with tributyl phosphate

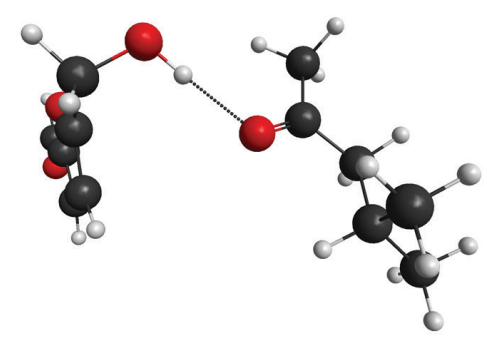

$\Delta \mathrm{E}=-6.82 \mathrm{kcal} \mathrm{mol}^{-1}$

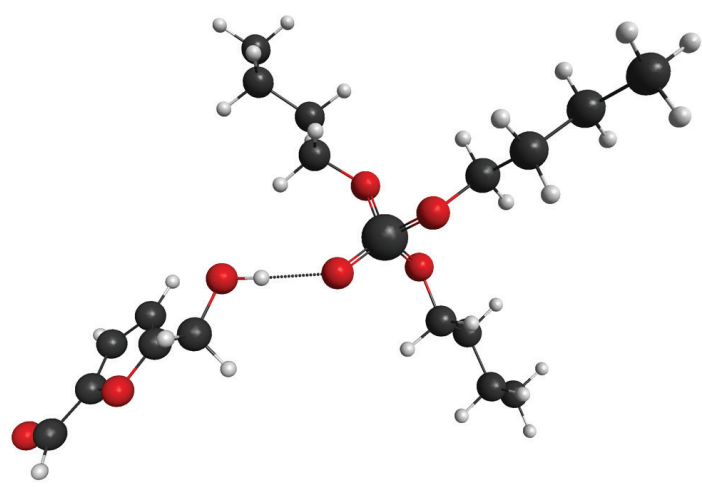

$$
\Delta \mathrm{E}=-8.69 \mathrm{kcal} \mathrm{mol}^{-1}
$$

Figure 2. Structures of the complexes of HMF with MIBK and tributyl phosphate. Geometries obtained at X3LYP/6-31(+)G(d) level and single point energies at X3LYP/TZVPP level. 
than with MIBK, providing a justification for the better extraction ability of tributyl phosphate.

\section{Conclusions}

The analysis of the best solvents for extraction of furfural, HMF and levulinic acid from aqueous solution, using theoretical calculations with the SMD model, has indicated that 4-heptanone is a very promising solvent. This claim is based on the predicted more negative free energy of transfer of the solutes, low solubility in water, low toxicity and boiling point below of furfural. In addition, our results also suggest that general $\mathrm{C}_{6}$ ketones are adequate solvents.

\section{Supplementary Information}

Supplementary data (complete tables of the calculated solvation free energies) are available free of charge at http://jbcs.sbq.org.br as PDF file.

\section{Acknowledgments}

The authors thank the agencies CNPq and FAPEMIG for support.

\section{References}

1. Wu, L.; Moteki, T.; Gokhale, A. A.; Flaherty, D. W.; Toste, F. D.; Chem 2016, 1, 32.

2. De, S.; Dutta, S.; Saha, B.; Catal. Sci. Technol. 2016, 6, 7364.

3. Melo, F. C.; Souza, R. F.; Coutinho, P. L. A.; Souza, M. O.; J. Braz. Chem. Soc. 2014, 25, 2378.

4. van Putten, R.-J.; van der Waal, J. C.; de Jong, E.; Rasrendra, C. B.; Heeres, H. J.; de Vries, J. G.; Chem. Rev. 2013, 113, 1499.

5. Saha, B.; Abu-Omar, M. M.; Green Chem. 2014, 16, 24.
6. Zhang, T.; Kumar, R.; Wyman, C. E.; RSC Adv. 2013, 3, 9809.

7. Lin, L.; Ma, S.; Li, P.; Zhu, T.; Chang, H.; J. Chem. Eng. Data 2015, 60, 1926.

8. Xin, K.; Song, Y.; Dai, F.; Yu, Y.; Li, Q.; Fluid Phase Equilib. 2016, 425, 393.

9. Mohammad, S.; Held, C.; Altuntepe, E.; Köse, T.; Sadowski, G.; J. Phys. Chem. B 2016, 120, 3797.

10. Männistö, M.; Pokki, J.-P.; Creati, A.; Voisin, A.; Zaitseva, A.; Alopaeus, V.; J. Chem. Eng. Data 2016, 61, 903.

11. Xiong, R.; Miller, J.; León, M.; Nikolakis, V.; Sandler, S. I.; Chem. Eng. Sci. 2015, 126, 169.

12. Blumenthal, L. C.; Jens, C. M.; Ulbrich, J.; Schwering, F.; Langrehr, V.; Turek, T.; Kunz, U.; Leonhard, K.; Palkovits, R.; ACS Sustainable Chem. Eng. 2016, 4, 228.

13. Marenich, A. V.; Cramer, C. J.; Truhlar, D. G.; J. Phys. Chem. B 2009, 113, 6378.

14. Zanith, C. C.; Pliego Jr., J. R.; J. Comput.-Aided Mol. Des. 2015, 29, 217.

15. Pliego Jr, J. R.; J. Braz. Chem. Soc. 2015, 26, 1737.

16. Marenich, A. V.; Cramer, C. J.; Truhlar, D. G.; J. Phys. Chem. B 2009, 113, 4538.

17. Guthrie, J. P.; J. Phys. Chem. B 2009, 113, 4501.

18. Xu, X.; Zhang, Q.; Muller, R. P.; Goddard III, W. A.; J. Chem. Phys. 2005, 122, 014105.

19. Gordon, M. S.; Schmidt, M. W. In Theory and Applications of Computational Chemistry; Dykstra, C. E.; Frenking, G.; Kim, K. S.; Scuseria, G. E., eds.; Elsevier: Amsterdam, 2005, p. 1167.

20. Schmidt, M. W.; Baldridge, K. K.; Boatz, J. A.; Elbert, S. T.; Gordon, M. S.; Jensen, J. H.; Koseki, S.; Matsunaga, N.; Nguyen, K. A.; Su, S.; Windus, T. L.; Dupuis, M.; Montgomery Jr, J. A.; J. Comput. Chem. 1993, 14, 1347.

21. Spackman, M. A.; J. Comput. Chem. 1996, 17, 1.

Submitted: June 3, 2017

Published online: July 20, 2017 